\title{
The role and choice criteria of antihistamines in allergy management - expert opinion
}

\author{
Piotr Kuna ${ }^{1}$, Dariusz Jurkiewicz², Magdalena M. Czarnecka-Operacz ${ }^{3}$, Rafał Pawliczak ${ }^{4}$, Jarosław Woroń5, \\ Marcin Moniuszko ${ }^{6,7}$, Andrzej Emeryk ${ }^{8}$
}

1'Division of Internal Medicine, Asthma and Allergy, Barlicki University Hospital, Faculty of Medicine, Medical University of Lodz, Lodz, Poland

${ }^{2}$ Department of Otolaryngology with Division of Cranio-Maxillo-Facial Surgery, Military Institute of Medicine, Warsaw, Poland ${ }^{3}$ Department and Division of Dermatology, Poznan University of Medical Sciences, Poznan, Poland

${ }^{4}$ Department of Immunopathology, Division of Allergology, Immunopathology and Dermatology, Faculty of Biomedical Sciences and Postgraduate Training, Medical University of Lodz, Lodz, Poland

${ }^{5}$ Department of Clinical Pharmacology, Faculty of Medicine, Medical College Jagiellonian University, Krakow, Poland

${ }^{6}$ Department of Allergology and Internal Medicine, Faculty of Health Sciences, Medical University of Bialystok, Bialystok, Poland

${ }^{7}$ Department of Regenerative Medicine and Immune Regulation, Medical University of Bialystok, Bialystok, Poland

${ }^{8}$ Department of Lung Diseases and Rheumatology, $2^{\text {nd }}$ Faculty of Medicine, Medical University of Lublin, Lublin, Poland

Adv Dermatol Allergol 2016; XXXIII (6): 397-410

DOI: $10.5114 /$ pdia.2016.63942

\begin{abstract}
Allergic diseases are the most common chronic conditions lasting throughout the patient's life. They not only cause significant deterioration in the quality of life of patients but also lead to significant absenteeism and reduced productivity, resulting in very high costs for society. Effective and safe treatment of allergic diseases is therefore one of the main challenges for public health and should be carried out by all the specialists in family medicine, internists and paediatricians in collaboration with allergists, otorhinolaryngologists and dermatologists. Antihistamines are most commonly used in the treatment of allergies. Several dozen drugs are available on the pharmaceutical market, and their generic forms are advertised widely as very effective drugs for the treatment of allergic diseases. What is the truth? What are the data from clinical trials and observational studies? Are all drugs equally effective and safe for the patient? According to a panel of experts representing various fields of medicine, inappropriate treatment of allergies can be very risky for patients, and seemingly equally acting medications may differ greatly. Therefore, a panel of experts gathered the latest data from the entire scientific literature and analysed the latest standards and recommendations prepared by scientific societies. This paper provides a summary of these studies and highlights the importance for the patient of the proper choice of drug to treat his allergies.
\end{abstract}

Key words: antihistamines, bilastin, allergic rhinitis, urticaria, allergy.

\section{Which antihistamines should be chosen according to current standards and recommendations?}

In the last few decades the incidence of allergic diseases has grown to epidemic status. According to the current data, more than 600 million people suffer from allergic rhinitis worldwide, approximately $25 \%$ of them in Europe. In the ECAP trial (Epidemiology of Allergic Diseases in Poland) as many as $30 \%$ of respondents reported allergic rhinitis, less than $7 \%$ mentioned urticaria, but over $40 \%$ of patients had positive skin tests with common inhaled allergens (e.g. plant pollen, dust mites, mould and animal hair). Despite this huge number of patients, these data are frequently underestimated, since allergic diseases are generally believed to be trivial and non-hazardous. However, it has already been proven that allergic rhinitis, asthma and urticaria are associated with a significant socioeconomic burden all over the world - regardless of region, development level and financial status. The total cost of allergic diseases brings both reduced quality of life and also direct costs of drugs and health services as well as indirect social costs such as the absence from work; it also decreases productivity and concentration and generates learning disorders and

Address for correspondence: Prof. Piotr Kuna MD, PhD, Division of Internal Medicine, Asthma and Allergy, Barlicki University Hospital, Faculty of Medicine, Medical University of Lodz, 22 Kopcinskiego St, 90-153 Lodz, Poland, phone: +48 426776951 ,

e-mail: piotr.kuna@umed.lodz.pl

Received: 29.08.2016, accepted: 18.09.2016. 
concomitant diseases. As allergic diseases occur mainly in the young population (which supports the senior population), their consequences are much more costly than those of diabetes, coronary heart disease or myocardial infarctions. In the USA alone, the costs of allergic rhinitis morbidity are estimated at over 25 billion dollars per year, of which approximately a half consists of indirect costs, resulting from insufficient disease control. In light of these studies it is not difficult to notice multidirectional benefits from effective management of allergic diseases, which improve both the patients' activity, productivity and quality of life and ultimately decrease the financial burden of healthcare systems. Efficient therapy of the most common allergic diseases is based mainly on oral antihistamines which are administered simply and, as a result, have the best compliance among the drugs recommended for the treatment of allergic rhinitis.

Histamine plays an important role in human physiology, influencing immunoregulation of the acute and chronic inflammatory response through 4 different types of receptors, called $\mathrm{H} 1, \mathrm{H} 2, \mathrm{H} 3$, and $\mathrm{H} 4$. Drugs classified in the first generation of antihistamines (sometimes called "classical" antihistamines) act non-selectively. Apart from all histaminic receptors they also block muscarinic, adrenergic (or adrenoreceptors) and dopaminergic receptors, causing cardiovascular, urinary and gastrointestinal adverse reactions. High lipophilicity and consequently easy crossing of the blood-brain barrier additionally intensify the most dangerous adverse events from the central nervous system, including drowsiness, decreased concentration, vigilance and psychomotor efficiency as well as reduced ability to learn and memorize, which is not related to sedation. However, in histamine-dependent allergic diseases the most important role is played by the $\mathrm{H} 1$ receptor, whose stimulation by histamine results in e.g. constriction of smooth muscles (obturation of inhalatory tract), increased permeability of endothelium (oedema) and stimulation of sensory nerves and cough receptors (pruritus, sneeze attacks, rhinorrhoea). Therefore, the discovery of compounds selectively acting on $\mathrm{H} 1$ receptors, currently called second generation drugs, could be considered the greatest breakthrough during more than 70 years of the history of antihistamines (Figure 1). On top of the high efficacy, the most important feature of these drugs is the incomparably better safety profile: some of them have the same (or even lower) number of adverse reactions as placebo. Due to the selective mechanism of action, low penetration of the central nervous system (CNS) and lack of interaction with adrenergic, muscarinic and dopaminergic receptors, the second generation drugs are devoid of the majority (if not all) of the side effects mentioned above; however, some of them could cause other serious adverse reactions, including body mass gain, inter-drug interactions or potentially life-threatening cardiotoxicity (in the majority of countries, these preparations have been withdrawn from the market) (Figure 2). Due to selective antagonism with $\mathrm{H} 1$ receptors, these drugs are highly effective in reduction of allergic rhinitis and urticaria symptoms, and the wide therapeutic index makes it possible to use them in very high doses without any concerns related to overdosing toxicity, which with the first generation drugs could lead

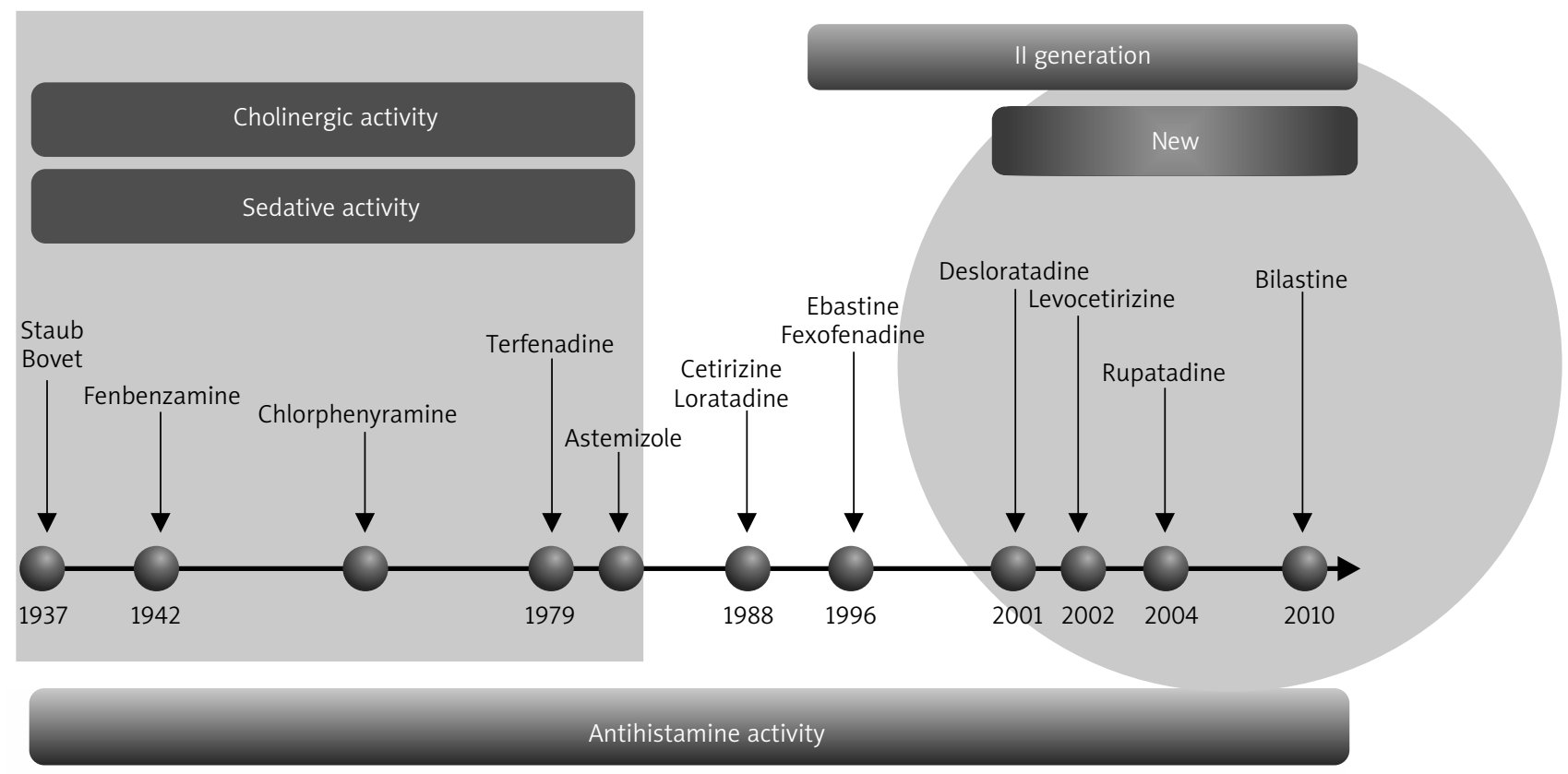

Figure 1. Development history of antihistaminic drugs 

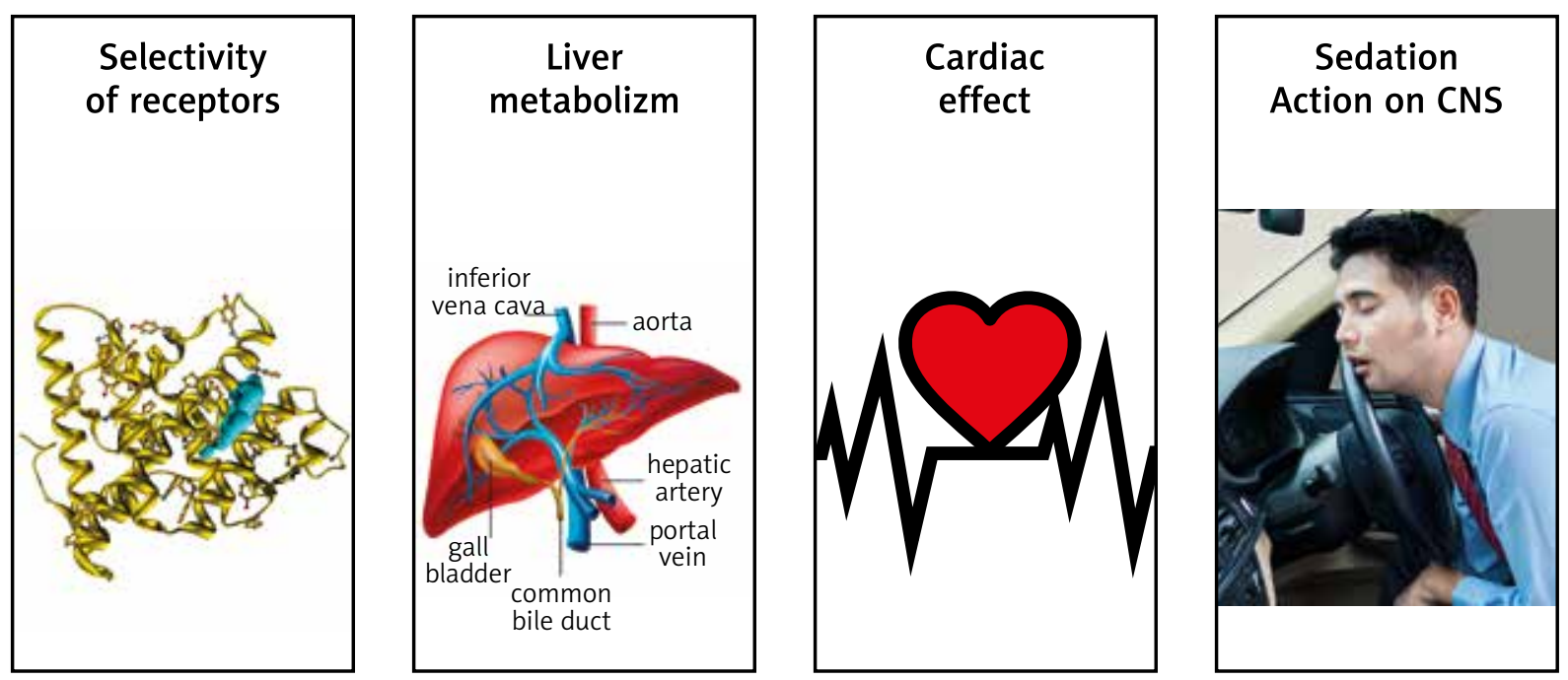

Figure 2. Adverse effects of antihistamines

to consciousness disturbances, coma, respiratory distress, and even death.

The described characteristics and easy usage as well as affordable price led to the inclusion of the second generation antihistaminic drugs in all global and local recommendations as the drugs of choice in all forms of allergic rhinitis and urticaria. The most frequently cited are ARIA (Allergic Rhinitis and its Impact on Asthma) guidelines, which discusses pharmacotherapy and presents the second generation anti-H1 drugs in the first place, recommending them in all adults and children [1]. Additionally, they highlight that the first generation drugs are not recommended wherever newer drugs are available. Almost the same recommendations could be found in the current EAACI/GA(2)LEN/EDF/WAO guidelines of urticaria management, in which non-sedative second generation antihistamines are recommended not only as the first but also as the second line drugs (after a maximum 4-fold dose increase in case of lack of efficacy of the standard dose administered for 2 weeks).

In light of the presented guidelines it is quite clear that non-sedative antihistamines are the backbone of allergic diseases treatment. However, the number of available drugs brings a dilemma: which drug should be chosen? Which criteria should be recognized in the decisionmaking process? Patients have different expectations, concomitant diseases and symptoms intensity, so the answer is not obvious, and each patient should be treated individually. From an average allergic perspective, the most important criteria of the drug choice are efficacy and price but - considering that not all second generation drugs are totally side effect-free in term of sedation, and their influence on ability to drive and learn is not commonly known by people - the safety profile and side effects should be especially taken into consideration in the drug selection process. Moreover, there are more and more patients in allergology practice treated due to concomitant chronic diseases, so inter-drug interactions are also an important factor, which should be taken into consideration treating allergic rhinitis and urticaria [2]. Thus, drugs which are not metabolized in the liver should be chosen.

As the second generation antihistamines available in Poland have comparable efficacy in controlling allergic rhinitis and urticaria symptoms, the most important factor distinguishing them seems to be the influence on the CNS and the safety of this therapy. Hence, when prescribing an anti-H1 drug according to recommendations we should first take into consideration the preparations with the smallest possible sedative effect, wide therapeutic index, beneficial pharmacokinetics and the lowest number of inter-drug interactions (Figure 3). This selection is of special importance in patients whose professions require concentration (such as driving), in which even a small sedative effect could lead to serious consequences (Figure 4). Here, we present the expert opinion regarding the role of bilastine in the management of allergic rhinitis and urticaria as a non-sedative second generation antihistaminic drug of an extremely favourable safety profile which does not influence the ability to drive vehicles and other machines, does not have any interactions with other drugs or alcohol, and (in allergic patients) decreases drowsiness even when compared to placebo $[3,4]$.

\section{The newest antihistamines in the management of allergic rhinitis and allergic conjunctivitis}

Allergic rhinitis is a complex of clinical symptoms caused by an inflammatory reaction including antibodies immunoglobulins E (IgE) targeting sensitizing aller- 
Incidence of treatment emergent adverse events (AEs) (\%)

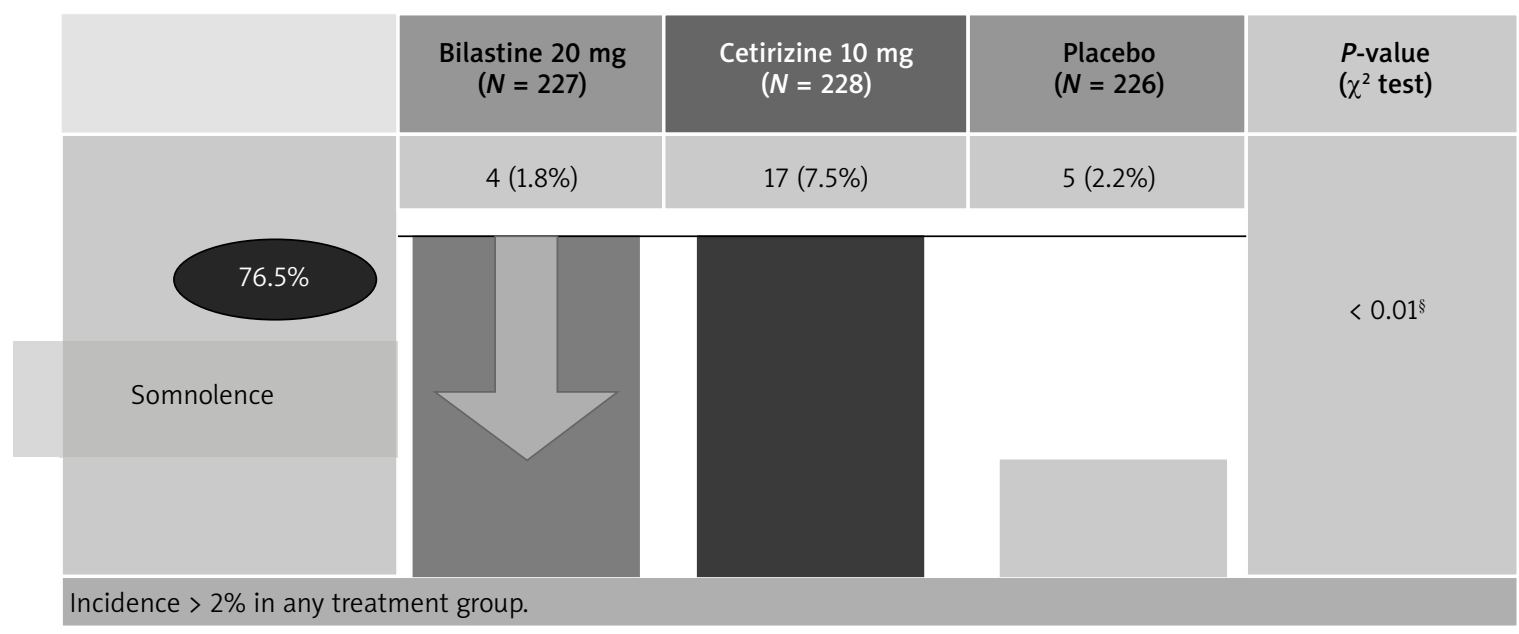

Analysis based on $\chi^{2}$ test; pair-wise comparisons: tbilastine vs. cetirizine: $p=0.01$; ${ }^{\S}$ placebo vs. cetirizine: $p=0.01 /$ bilastine vs. cetirizine; $p<0.01$; \#placebo vs. bilastine: $p=0.03$ /bilastine vs. cetirizine $p<0.01$; *bilastine vs. cetirizine $p=0.01$.

Figure 3. Efficacy and safety of bilastine $20 \mathrm{mg}$ compared with cetirizine $10 \mathrm{mg}$ and placebo for the symptomatic treatment of seasonal allergic rhinitis (somnolence) [3]

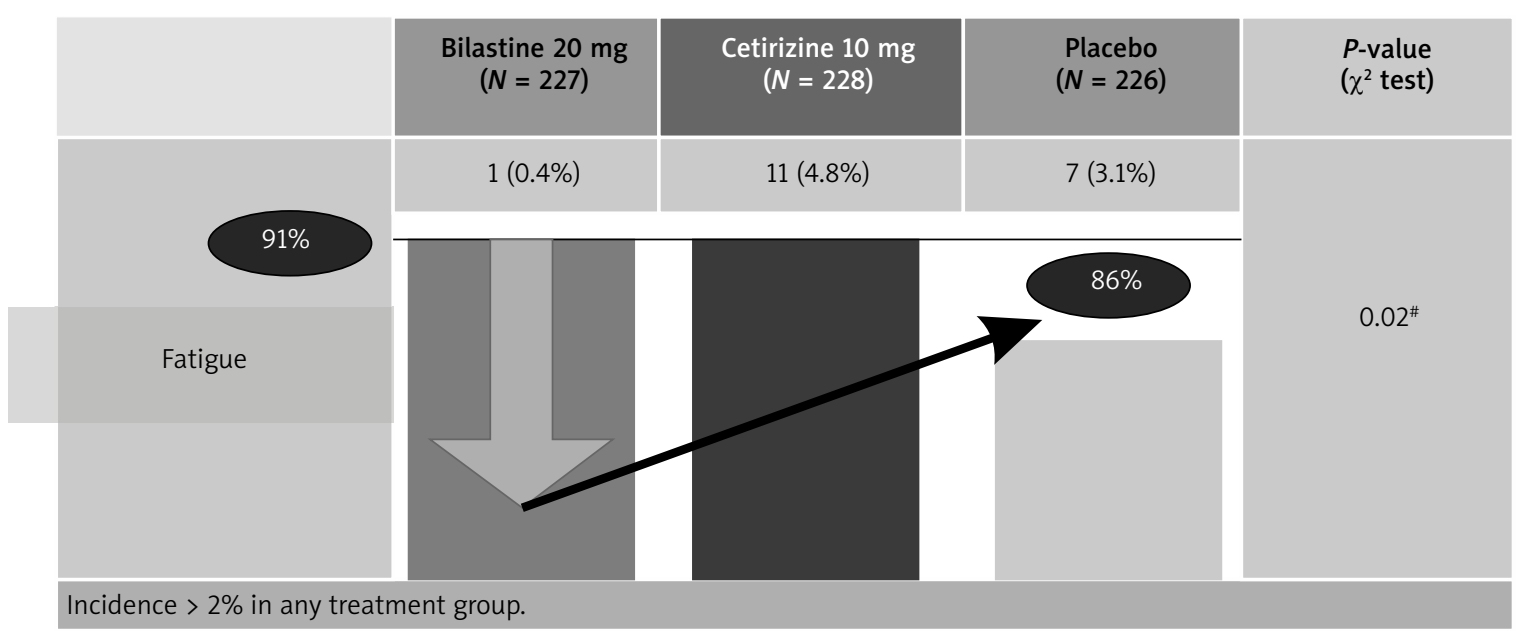

Analysis based on $\chi^{2}$ test; pair-wise comparisons: ${ }^{\ddagger}$ bilastine vs. cetirizine: $p=0.01$; ${ }^{\S}$ placebo vs. cetirizine: $p=0.01 /$ bilastine vs.

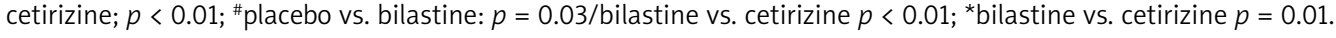

Figure 4. Efficacy and safety of bilastine $20 \mathrm{mg}$ compared with cetirizine $10 \mathrm{mg}$ and placebo for the symptomatic treatment of seasonal allergic rhinitis (fatigue) [3]

gens. The clinical symptoms of allergic rhinitis include rhinorrhea, nasal congestion, itchy nose and sneezing [5]. These symptoms are recurrent and intensify after contact with the allergen. Sometimes the patient's complaints include concentration disturbance, fatigue, or snoring.

Allergic conjunctivitis frequently coincides with allergic rhinitis. Eye symptoms, including watering, redness and itching, usually develop before nasal symptoms.
Allergic rhinitis and allergic conjunctivitis are concomitant so frequently that in many countries they are defined as one condition (e.g. allergic rhinoconjunctivitis).

The symptoms of allergic rhinitis significantly reduce quality of life; they adversely influence social life and decrease performance in learning and work. Untreated (or undertreated) allergic rhinitis (incompatible with recommendations) could lead to complications in the lower respiratory tract, paranasal sinuses and ears. 
In the ECAP trial the incidence of allergic rhinitis was assessed and attributed to $22.4 \%$ of the population under research [6].

According to triggering allergens and duration of exposure time, allergic rhinitis was previously divided into seasonal, perennial and occupational. In 2001, an international workgroup proposed an ARIA statement with a new classification of allergic rhinitis based on duration of clinical symptoms. They distinguished periodic allergic rhinitis (with symptoms not shorter than 4 days per week or shorter than 4 weeks) and chronic allergic rhinitis (with symptoms lasting for more than 4 days per week and longer than 4 weeks) [5]. Depending on the intensity of symptoms, allergic rhinitis could be split into mild and moderate/severe.

The choice of drugs for allergic rhinitis treatment is based on its intensity level and clinical symptoms. In each case, allergen-specific immunotherapy should be considered.

Updated recommendations indicate that the second generation antihistamines (without a sedative effect) and local glucocorticosteroids are the main drugs used in allergic rhinitis management. Although the second generation antihistamines reduce itching and sneezing highly efficiently, glucocorticosteroids effectively reduce nasal congestion, which is a symptom of delayed allergic reaction.

According to the recommendations published in ARIA and PoSLeNN (Polskie Standardy Leczenia Nieżytów Nosa) documentation, the basic treatment of patients with any form of chronic allergic rhinitis as well as in moderate and severe periodic allergic rhinitis should be based on local glucocorticosteroids [7, 8], and oral antihistamines should complement allergic rhinitis therapy. The use of oral antihistamines is specifically justified in patients with concomitant extra-nasal symptoms: pruritus, eye watering and redness, symptoms from the mouth and pharyngeal mucosa as well as skin signs. The second generation oral antihistamines are indicated, including those without a sedative effect. Allergic rhinitis involves the nasal cavity, and it is also a systemic disease, so the systemic treatment would relieve all relevant symptoms of allergic inflammation.

The nasal cavities should be investigated before local administration of glucocorticosteroids. In the case of very tight nose congestion local drugs are ineffective because they could not be delivered to the entire nasal mucosa. Patients with anatomical variations (e.g. nasal septum deviation, hyperplasia of nasal turbinate) have additional restrictions with administration of intranasal drugs. Treatment with intranasal glucocorticosteroids could be associated with adverse reactions (burning sensation, pain, bleeding) which could discourage patients from taking such drugs. The full effect of the drug could be apparent at 5-7 days of its administration; however, the relief of symptoms could be observed within a few hours after the administration of the second generation antihistamines. This is very important in patients with periodic allergic rhinitis, when the duration of the condition is shorter than the onset of action of intranasal glucocorticosteroids. Physicians and patients are also discouraged by the quite widespread phobia of steroids. For these reasons, many patients prefer to use oral drugs instead of intranasal drugs. Therefore, the therapy with the second generation antihistamines seems to be more beneficial. Favourable tolerability and safety profile of the drug should always be considered when taking a decision on the choice of an antihistamine. Bilastine is the most modern drug in this group, and meets the criteria mentioned above.

In a randomized, double-blinded, placebo-controlled clinical trial Horaka et al. [9] compared in Vienna Challenge Chamber conditions outside the pollen season the efficacy of bilastine, cetirizine and fexofenadine in relieving nasal and extra-nasal (mainly ocular) symptoms of allergic rhinitis. They found that bilastine in a dose of $20 \mathrm{mg}$ is effective in relieving the nasal and extra-nasal symptoms of seasonal allergic rhinitis. Bilastine is characterized by fast onset of action already at one hour after administration, and the effect lasted over 26 h. Bilastine is more effective when compared to placebo in relieving allergic rhinitis symptoms, and its efficacy in relieving the nasal symptoms of allergic rhinitis was comparable with cetirizine. Compared to fexofenadine in the dose of $120 \mathrm{mg}$, bilastine in the dose of $20 \mathrm{mg}$ is significantly more effective in relieving nasal symptoms of seasonal allergic rhinitis in the period between the $22^{\text {nd }}$ and $26^{\text {th }} \mathrm{h}$ after its administration.

In another randomized, double-blinded clinical trial, the efficacy of bilastine in the dose of $20 \mathrm{mg}$ and cetirizine in the dose of $10 \mathrm{mg}$ was compared with placebo in 681 patients from 61 European sites [3]. The results showed that bilastine in the dose of $20 \mathrm{mg}$ administered once a day for 2 weeks was more effective than placebo in relieving the symptoms of seasonal allergic rhinitis. Bilastine showed the same efficacy as cetirizine in relief of nasal and extra-nasal symptoms of allergic rhinitis for the entire 14 days of treatment. Bilastine decreased the intensity of patient's discomfort associated with allergic rhinitis comparably to cetirizine.

In a randomized, double-blinded, placebo-controlled clinical trial bilastine (20 mg), desloratadine (5 mg) and placebo were administered to 721 patients at the age between 12 and 70 years with seasonal allergic rhinitis [10]. It was found that bilastine administered for 2 weeks in a dose of $20 \mathrm{mg}$ efficiently relieved the symptoms of seasonal allergic rhinitis. Additionally, bilastine significantly reduced the symptoms of allergic rhinitis as compared to placebo. Efficacy of bilastine and desloratadine in relief of nasal and extra-nasal symptoms of allergic rhinitis after 7 and 14 days was similar. Comparably to desloratadine, bilastine improved the quality of life in patients with allergic rhinitis. 
In a randomized, double-blinded, placebo-controlled clinical trial Sastre et al. [11] compared the efficacy of bilastine and cetirizine in the treatment of allergic rhinitis. It was found that the efficacies of bilastine and cetirizine are similar and significantly higher when compared to placebo. Additionally, bilastine was found to be effective, safe and well tolerated in 12 months of treatment.

To conclude, it should be stated that bilastine is an effective drug in relieving nasal and ocular symptoms of allergic rhinitis, and it shows fast and durable activity after the administration of a single dose. The efficacy of bilastine is comparable with the efficacy of cetirizine, desloratadine and fexofenadine in relieving the symptoms of allergic rhinitis. Bilastine significantly improves quality of life in patients with allergic rhinitis.

\section{The newest antihistaminics in the management of urticaria}

Urticaria has always been related to the antihistaminic treatment. It results from the fact that histamine is one the basic mediators responsible for the development of all the main-symptoms of the disease, such as erythema, oedema, pruritus/itching and burning sensation. However, nowadays it has become evident that besides histamine a very wide panel of various mediators is also involved in urticaria clinical appearance, and both synthesis and release of these mediators are dependent on different, sometimes complex etiologic and/or triggering factors, which unfortunately often remain unclear [12, 13].

Depending on the duration of clinical symptoms (the time since the first episode of urticarial wheals), urticaria can be classified as acute (up to 6 weeks) or chronic (over 6 weeks). From the clinical point of view, causes and coexisting triggering factors are highly difficult to define in patients with chronic spontaneous urticaria. Generally, autoimmune (autoreactive) or infection-related causes (focuses of latent infections, Helicobacter pylori, parasitic infestations, etc.) may be identified. However, there are still remaining clinical cases which need to be classified as chronic spontaneous urticaria of an unknown cause. Within this group of patients urticarial wheals (often accompanied by symptoms of angioedema) erupt spontaneously, without either any specific or predictable cause or triggering factor.

The current urticaria classification was prepared, presented and published in 2014 by a group of experts representing international scientific societies in allergology and dermatology (Table 1) [14].

The general rules related to the management of chronic urticaria were also presented in the guidelines published in 2014 (Figure 5). Thus, in case of the lack of efficacy of the classical dose of a modern antihistaminic, the dose should be increased, sometimes even up to four-fold. If the treatment is still ineffective, it should be in addition to the high dose of the new generation antihistaminic supplemented with cyclosporine A, omalizumab or montelukast. Obviously, the exchange of a modern antihistaminic for another medication of the same group (obviously of different pharmacological characteristics) should also be individually considered. Moreover, it should be pointed out that evidence of the safety and efficacy of high dose-treatment with antihistaminics has been proven and is available only for some selected modern antihistamines, and therefore potential medications of choice should be limited to this group only. Obviously if exacerbations in the course of urticarial and/or angioedema symptoms develop, a short-term (up to 1 week) systemic treatment with glucocorticosteroids is possible. It should be highlighted that systemic glucocorticosteroids should never be regarded as the therapy of choice in patients with chronic spontaneous urticaria. Unfortunately, there are still many doubts about the proper understanding and clinical implementation of guidelines regarding diagnosis and therapy of chronic urticaria. It has been highly surprising to find out that only $30 \%$ of physicians responsible for treatment of urticarial patients

Table 1. Classification of chronic urticaria subtypes (presenting with wheals, angioedema, or both) (based on [14])

\begin{tabular}{|c|c|}
\hline \multicolumn{2}{|c|}{ Subtypes of chronic urticaria } \\
\hline Chronic spontaneous urticaria & Induced urticaria \\
\hline \multirow{9}{*}{$\begin{array}{l}\text { Spontaneous eruption of wheals, angioedema or both } \\
\text { symptoms } \geq 6 \text { weeks of known or unknown cause }\end{array}$} & Symptomatic dermographism (urticaria factitia) \\
\hline & Cold urticaria (contact cold urticaria) \\
\hline & Delayed pressure urticaria (pressure urticaria) \\
\hline & Solar urticaria \\
\hline & Hot urticaria (hot urticaria, contact hot urticaria) \\
\hline & Vibration-induced angioedema \\
\hline & Cholinergic urticaria \\
\hline & Contact urticaria \\
\hline & Water urticaria \\
\hline
\end{tabular}


have actually familiarised themselves appropriately with that important paper.

Another exceptionally important fact which should be underlined (and which was also reflected in the current guidelines) is that in the treatment of urticaria two or more antihistamines should never be combined. For example, it is a grave error to recommend two tablets of bilastine in the morning, and 1-2 tablets of levocetirizine in the evening. Unfortunately, despite previous guidelines from the year 2009 and the new updated version, such mistakes still occur in the daily clinical practice. It should be strongly underlined that this type of approach is simply wrong: higher efficacy of a combined antihistaminic treatment (2 or more antihistaminics combined together) has never been confirmed; and finally the risk of combined adverse reactions to the administered drugs is significantly high.

Bilastine is a modern antihistaminic, which was thoroughly and specifically evaluated in the treatment of patients with chronic spontaneous urticaria related to different causes as well as in patients with chronic induced urticaria (e.g. cold-induced chronic urticaria). There is comprehensive documentation available regarding both the efficacy and safety of this medication administered in high doses and, even more importantly, there is also well-documented in vivo (microdialysis of the skin) antiinflammatory activity of bilastine. The studies performed by Zuberbier et al. provide the best evidence [15-18].

From the clinical standpoint, it is also very important to remember that the old generation of antihistaminics is absolutely not indicated in the treatment of chronic spontaneous urticaria, and only in case of acute urticaria and/or angioedema if parenteral treatment is necessary may this group of antihistaminics be administered. However, in such cases systemic glucocorticosteroids should be concomitantly required. It is considered to be the preventive treatment in terms of possible development of a systemic anaphylactic reaction [19].

To summarize, chronic spontaneous urticaria still remains a difficult challenge for us. Characterized by an often unclear and highly complex aetiopathogenesis, it requires treatment based on both wide clinical experience and knowledge of current guideline. The proper, selective choice of modern antihistaminic medication should be based on robust knowledge and available evidence regarding both efficacy and safety of high-dose antihistaminic treatment.

\section{Cardiovascular safety of antihistamines}

The newest antihistamines of the second generation currently registered and used in Poland have relatively high cardiovascular safety. It results from their relatively high receptor selectivity and use of centralized electrocardiography (ECG) evaluation by cardiologists in all phases of clinical trials with the new drugs. Finally, this leads to early elimination of drugs which (albeit to

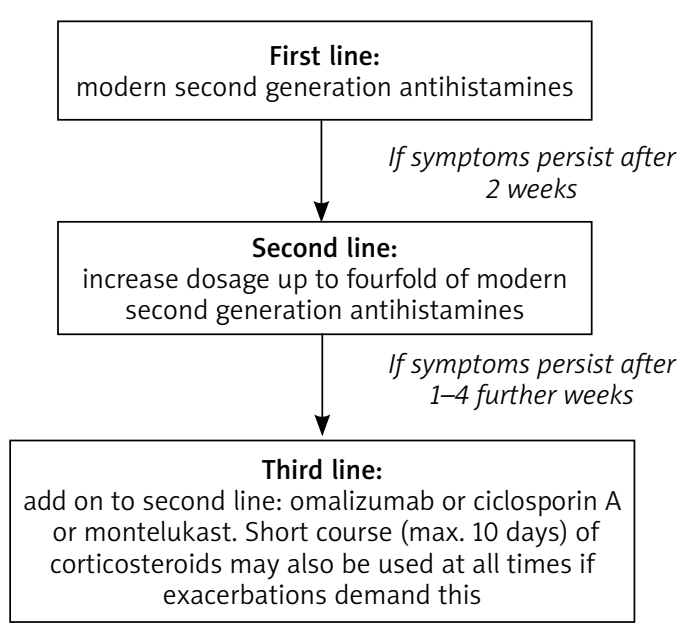

Figure 5. Recommended treatment algorithm for chronic spontaneous urticaria [14]

a small extent) influence ion channels. The review of the whole published literature showed that to date only 171 publications have addressed the problem. Astemizole was one of the first drugs which led to more interest in the influence of antihistamines on the heart. It is interesting that the first published data were favourable [20]. Only the later clinical studies in human and experimental animal studies indicated that the drug had the ability of strongly inhibiting potassium channels in cardiac muscles cells. The consequence of that process is delayed repolarization of ventricular muscle cells, which is clinically presented as the prolongation of QTc interval. Its direct result is a significant increase of risk of life-threatening ventricular arrhythmias. However, the clinical data show that this phenomenon is observed mainly in the case of administration of high doses, exceeding registered and recommended doses, metabolic interactions or in specific situations, e.g. hypoxia of cardiac muscle cells [2128]. The drugs mentioned above were withdrawn from the market due to relatively high risk of cardiovascular adverse events [26-28]. Any concerns whether blockade of potassium channels is an antihistamines class effect were quickly dispelled by indicating that this process is not associated with drugs other than the ones mentioned above $[21,29,30]$. Since then, in clinical trials with all antihistamines their clinical features regarding the influence on QTc interval have been meticulously assessed.

New guidelines regarding treatment of chronic urticaria slightly changed our view on the potential and actual safety of antihistamines. Established management including increasing the standard dose of the antihistamine to a four-times higher dose could potentially prolong the QTc interval. The majority of antihistamines have not been subjected to clinical studies with those doses conducted in adequately large populations. Moreover, after the publication of the guidelines there were 
also additional publications that showed that in some cases and for some antihistamines a four-times higher dose could be inefficient - and possibly in such cases even a six-fold higher dose should be used in the treatment of chronic urticaria. There have been no published clinical trials addressing the problem of cardiovascular safety of antihistamines in doses six times higher than standard doses. Relatively well-designed studies regarding cardiovascular safety were conducted with bilastine. This drug administered in doses from $20 \mathrm{mg}$ up to $100 \mathrm{mg}$ (a five-fold higher dose than registered) in 30 healthy volunteers did not influence either the morphology of the ECG signal or the QTc interval [31]. The QTc prolongation did not exceed $5.0 \mathrm{~ms}$ (95\% Cl: 2.0-8.0) for high doses of the drug. Moreover, when bilastine was administered in combination with ketoconazole $400 \mathrm{mg}$, the QTc interval and morphology of the ECG signal were similar to placebo [31]. Those clinical trials were conducted according to recommendations of E14 - the International Conference of Harmonisation (ICH) [31]. None of the conducted clinical trials showed any influence of bilastine on the morphology of the ECG signal and QTc interval. Thus, it could be stated that the cardiovascular safety of bilastine is very high, and the influence of the drug on morphology of the ECG signal and cardiac muscle repolarization is the same as that of placebo [10, 15, 32-44].

\section{Use of antihistamines in treatment of viral infections of the upper respiratory tract}

Taking into consideration the pathophysiology of upper respiratory tract infection, the non-sedative antihistamines of the second generation could have symptomatic activity, improving quality of life of those patients. This question has been relatively rarely studied, and to date fewer than 100 articles on this topic have been published. The results of a meta-analysis of available clinical studies showed that drugs from this therapeutic class could have important symptomatic activity during the initial period, especially in the first days of infection [45]. They are effective mainly in adult patients [45]. It seems that apart from the relatively weak effect blocking the $\mathrm{H} 1$ receptor, the extra-receptor anti-inflammatory activity could be even more important. For example, bilastine, inhibiting release of IL-6 and IL-8, could potentially have some effect [15]. Obtaining convincing results of clinical trials and formulating unambiguous conclusions require further in vivo and in vitro studies.

\section{Past, present and future of antihistamines. What should be considered from the pharmacologist's perspective?}

The $21^{\text {st }}$ century gives us the possibility of the practical use of personalized pharmacotherapy, which includes, in the broad sense, safety of therapy as one of the most important criteria of drug choice. This is a direction of evolution and development of particular therapeutic groups, and the best examples are some antihistamines, which are characterized by high effectiveness and also by an optimal safety profile. The latter factor includes the reduction of the risk of adverse events and also the reduction of the risk of interactions when antihistamines are administered as a component within a multi-drug therapy.

The introduction of the second generation drugs brought many benefits for patients with indications for these drugs. The biggest progress was seen according to the possibilities of adjusting the drug to the individual patient's need with additional reduction of the number and intensity of adverse events, what directly translates into patient's compliance. Contrary to the first generation drugs, the second generation shows high selectivity against type 1 histamine receptors with minimal or lack of affinity to other groups of receptors, which does not intensify the therapeutic effect but increases the risk of occurrence of adverse events.

Low (or even a lack of) affinity to other groups of receptors, such as muscarinic, $\alpha 1$ adrenergic and dopaminergic, limits the occurrence of adverse events, e.g. visual disturbances, dry mouth, sedative effect, and difficulties in passing urine, which all reduce the quality of life. As it has been previously mentioned, they frequently cause incompliance, and even treatment interruption, which translates into treatment efficacy and final outcomes.

Lipophilicity and distribution volume of the second generation drugs are not so large as for the first generation drugs, which prevents their crossing of the bloodbrain barrier and induction of adverse events in the CNS including excessive sedation, drowsiness, fatigue and significant reduction of psychomotor efficiency.

Lack of influence on central $\mathrm{H} 1$ receptors prevents appetite increase and weight gain. This is especially important in patients with diabetes, hypercholesterolaemia or overweight patients because body mass gain increases insulin resistance and the likelihood of related complications.

Very beneficial changes in the mechanism of action of the antihistamines of the second generation led to the situation in which they are the preferred group of drugs in clinical practice.

Currently, there are very few or even no indications for the first generation drugs. They are used for a short period as components of complex drugs administered in the symptomatic treatment of cold and influenza, where they act mainly as anticholinergics. In patients with rhinitis with concomitant nasal congestion $\alpha 1$ adrenolytic activity could even be harmful.

Unquestionably, the second generation drugs form a category that is not homogeneous. Their pharmacokinetic and pharmacodynamic characteristics determine their features, which are frequently criteria of choice. 
It should be remembered that allergic reaction and concomitant symptoms very often coexist with other acute or chronic diseases. Thus, during administration of antihistamines the high risk of both pharmacokinetic and pharmacodynamic interactions should be considered. From a practical point of view, the pharmacokinetic interactions are the most important in this group of drugs, and they take place during the metabolism stage via isoenzymes of cytochrome P450.

Therefore, the risk of adverse interactions unquestionably increases when antihistamine is metabolized via cytochrome P450. To prevent inter-drug interactions and their clinical consequences and the need for treatment modification, drugs not metabolized via CYP450 should be chosen. One such drug is bilastine. It should be highlighted that one of the most important criteria of antihistamine choice is the risk of interaction in multidrug therapy, also taking into consideration that allergic diseases and asthma are chronic diseases, which especially increases polypragmasia risk. Available pharmacoepidemiological studies indicate that the risk of excessive polytherapy increases four to five times in patients with allergic diseases. Other observations supplement this hypothesis and confirm that the risk of excessive polytherapy is especially high during treatment of cardiovascular disease, analgesic treatment and therapy of allergic diseases.

Additionally, it is worth remembering that there is a notable risk of interactions within the antihistamine group, which is associated with characteristics of particular drugs.

Bilastine is one of the newest drugs in the second generation antihistamines. It has a very interesting activity profile because bilastine is a new molecule, with its own pharmacological characteristics. It should be underlined, as there are many available antihistamines after "metamorphosis", which are metabolites or isolated enantiomers of basic compounds, e.g. levocetirizine and desloratadine. As enantiomers and metabolites often maintain the pharmacodynamic specificity of a native drug, this "metamorphosis" does not always bring significant benefits associated with drug activity. Hence, this could have a very low influence on decreasing the risk of interactions, especially pharmacokinetic, which could occur with other concomitantly administered drugs.

Bilastine is a drug of high affinity to the $\mathrm{H} 1$ receptor. It does not bind to muscarinic receptors and does not have any sedative activity. Bilastine does not show any adverse interactions with other concomitant drugs as it does not undergo liver metabolism. The drug is excreted with faeces in an unchanged form, but a small portion of it is excreted with urine. Bilastine dosage should not be modified in patients with renal and hepatic insufficiencies. It could be safely taken by patients driving vehicles, and it does not influence the QTc interval in the ECG record, which significantly improves the cardiovascular safety profile as compared to the class.

Concomitant administration of drugs influencing activity of glycoprotein P or polypeptides transporting organic anions or their substrates could change the concentration of bilastine. Administration of ketoconazole or erythromycin at the same time increases bilastine area under the curve (AUC) and Cmax, whilst diltiazem increases the drug plasma concentration. Ritonavir and rifampicin could decrease the bilastine plasma concentration.

Bilastine does not intensify the depression of the CNS caused by lorazepam or alcohol-induced disturbances. In the case of other antihistamines, especially penetrating to the CNS, their intensification of central depression should be considered. Tricyclic antidepressants and other cholinolytic drugs intensify the anti-muscarinic effect.

Cholinolytic activity of antihistamines weakens the effect of mucolytic and mucokinetic drugs, so in patients who use them it is recommended to choose an antagonist of the $\mathrm{H} 1$ receptor, which is deprived of anti-muscarinic activity - and bilastine is such a drug. Antihistamines easily penetrating to the CNS intensify sedative activity and increase the risk of adverse events occurring concomitantly with administration with phenothiazines, fenspiride, benzodiazepines and antidepressants with sedative activity (mianserin, mirtazapine, trazodone). During bilastine administration, such interactions are of no clinical importance.

In patients driving motor vehicles and mechanical machines, the sedation and prolonged reaction time are a very important problem. It should be remembered that during long-term administration of sedative antihistamines the phenomenon of reduction of psychomotor efficacy is not decreased. However, this adverse event is changed qualitatively. Practically, it means that patients do not have any individual feelings of prolonged reaction time and sedation, but it does not mean that a patient is fully efficient.

Using antihistamines with sedative activity is part of the bigger problem of road accidents, which is connected to the public health area. Every fifth accident is caused by patients taking drugs which could impair their psychomotor efficacy. There are some publications comparing impairment of psychomotor efficacy after administration of antihistamines of the old generation to alcohol-induced effects. For instance, the effect after taking clemastine is the equivalent of consumption of $0.8 \mathrm{~g} / \mathrm{l}$ of alcohol. Bilastine does not produce such impairment of psychomotor efficacy, which is otherwise possible during administration of cetirizine (the most frequently used drug in Poland). There are more details on this topic in the literature presenting a problem of adverse events in clinical practice. The antihistamines of the first generation as well as cetirizine, being a metabolite of hydroxyzine, could lead to reduction of attention and vigilance, contributing to impairment of psy- 
chomotor efficacy. Nevertheless, contrary to the common belief this has a negative reflection not only in the working population (however, the effect in this group seems to be the strongest). Children taking cetirizine could have a problem with learning and with concentration at school, resulting both from antihistamine activity and also from anticholinergic action of that drug. This is a common problem of children, parents and teachers. Sometimes parents and teachers are unable to define an underlying reason for school problems, and they actually refer to the activity of these drugs.

Falls as a consequence of pharmacotherapy also have some importance. Hydroxyzine and cetirizine are close after benzodiazepines and opioids on the list of drugs increasing the risk of falls in elderly patients.

There are known factors in practice which increase the probability of sedation as a result of treatment with antihistamines. They are as follows: female gender; very young or very old age; hepatic or renal insufficiency; heart failure; obesity; hypothyroidism; hypotension; dehydration; slow acetylator phenotype.

According to reported data, pharmacological aspects of drugs' activity clearly translate into clinical activity, so they have to be taken into account even during choice of symptomatic drugs, including antihistamines. The adverse events profile and interactions of antihistamines constitute important criteria of their choice in clinical practice. Failure to take this into consideration during combined therapy could lead to complications of allergic disease management.

Bilastine shows the lowest risk of interactions with other drugs as compared with different antihistamines, which is associated with its pharmacokinetic and pharmacodynamic profile [46-58].

\section{Antihistamines and immune system. Preliminary results of a study evaluating mechanisms of anti-inflammatory action of bilastine}

For a long time, several actions of antihistamines have been attributed to their putative anti-inflammatory features, not directly associated with the histamine receptor. The majority of those studies were conducted in vitro and demonstrated smaller or greater ability of antihistamines to, among other things, decrease the expression of adhesive molecules on the surface of endothelial cells as well as epithelium in the upper and lower respiratory tract, reduce eosinophilia in tissues involved in the allergic inflammatory process, shorten eosinophil survival time, decrease expression of inflammatory cytokines (IL-1 $\beta$, IL-4, IL-6, IL-7, IL-8, GM-CSF), inhibit release of metalloproteinases, reduce oxidative stress and decrease replication of rhinoviruses in epithelial cells in the respiratory tract. A recent study performed by Krause et al. [15] showed in a clinical setting that use of bilastine in a four-fold higher dose as compared to a standard dose in patients with cold urticaria led to a significant decline of IL- 6 and IL-8 concentrations assessed after skin microdialysis a few hours after a provocation test with cold. This study confirmed in vivo anti-inflammatory activity of bilastine; however, it did not identify either the source of cytokines' release or their further influence on the immune response. Therefore, we set out to perform a more precise assessment of the effects of bilastine on different arms of the immune response. We analysed the effects of different bilastine concentrations on such crucial orchestrators of the immune response as different subpopulations of monocytes that are precursors of macrophages and dendritic cells and different subpopulations of CD4+ and CD8+ lymphocytes with either regulatory or effector potency. Currently, our large-scale basic research is being conducted, evaluating the effect of both standard and higher doses of bilastine on phenotype as well as functional potential of above-mentioned subpopulations of immune cells. The current studies on bilastine are among the first such comprehensive trials to evaluate the effects of antihistamines' activity on different elements of cell-mediated immunity. The results of these studies will give a chance to more precisely assess immunomodulatory activity of bilastine, and in consequence contribute to better understanding of its mechanisms of action in management of such complex inflammatory diseases as chronic urticaria.

\section{Antihistamines in paediatric patients and patients with asthma}

The second generation antihistamines that are currently available and the most frequently used fail to meet all expectations of paediatricians and allergologists, especially in terms of safety and adverse events. Moreover, not all formulations of these drugs are acceptable for children. An ideal oral antihistamine of the second generation dedicated to paediatric patients should meet the following criteria [59-61]:

- Very high selectivity against the $\mathrm{H} 1$ receptor (lack of extra-receptor activity).

- Fast onset of action.

- Long biological half-time (possibility to administer once a day).

- Registration for patients aged 0-18 years (the same drug in all age groups, availability of different forms of the drug).

- Very good tolerability.

Indications for the use of antihistamines in children are generally similar to indications in adults. However, there is not such strong evidence for some indications in this population as in adults. The first generation antihistamines are not indicated in children due to many adverse events connected to activity of these drugs against other than $\mathrm{H} 1$ receptors in peripheral tissues' (muscarinic, $\alpha$-adrenergic and serotonin receptors) and 
$\mathrm{H} 1$ receptors in CNS, or cardiac ion channels [62]. A few years ago Schad and Skoner summarized the role and position of antihistamines for use in children [63]. In this systemic review of indications for using antihistamines in children, the authors emphasised that the strongest recommendations for antihistamines were established for allergic rhinitis and allergic conjunctivitis as well as urticaria (evidence category I, strength of recommendation A). Slightly weaker recommendations are for allergic conjunctivitis and mosquito bites or eosinophilic cellulitis (Wells' syndrome) (evidence category I, strength of recommendation B). Other considered or possible indications, such as asthma or otitis media, failed to receive positive recommendations in this review. Benedictis et al. presented a similar statement [64].

\section{Allergic rhinitis and allergic conjunctivitis}

In light of the ARIA 2008 and ARIA 2010 documents, the second generation antihistamines (oral or intranasal) are the drugs of first line treatment of periodic allergic rhinitis of mild or moderate/severe clinical course and mild chronic allergic rhinitis with evidence of strength of recommendation $A[1,7]$. Antihistamines are also a component of therapy of chronic allergic rhinitis of moderate/severe clinical course as an add-on drug to nasal glucocorticosteroids [7]. The second generation antihistamines could also be administered in paediatric patients over 12 years old - in combination with nasal glucocorticosteroids [65].

\section{Urticaria}

In light of two current consensuses of combined groups of experts from several organizations (EAACI, $\mathrm{Ga}^{2} \mathrm{LEN}$, EDF, WAO and/or UNEV), each case of urticaria in children should be treated with modern second generation antihistamines (strong recommendation, high strength of evidence), and in chronic urticaria they are even the drugs of choice $[14,66]$. When clinical symptoms remain for over 2 weeks, the second generation antihistamines should be administered in a two-to-four times higher dose. When despite such management the symptoms still persist, it should be considered to add a drug from another therapeutic class (as in adults) [14] or to exchange one antihistamine of the second generation for another [62]. The second generation antihistamines should be administered in the lowest effective dose but not on demand (strong recommendation, high strength of evidence) [14].

\section{Food allergy}

Antihistamines could immediately reduce clinical symptoms and decrease the severity of the clinical course of some food allergy reactions in children [67]. However, this recommendation is very weak.

\section{Allergic conjunctivitis}

There is a reasonable basis to use antihistamines in the treatment of allergic conjunctivitis in children [68]; however, there is little reliable evidence of efficacy in this indication. Despite this, the antihistamines of the first and the second generations are commonly used by paediatricians in this disease, although as a supplementary therapy only [69, 70]. The first generation antihistamines (with sedative and anti-itching activity) could be helpful in children with sleep disorders due to pruritus and in severe forms of allergic conjunctivitis [71]. Some antihistamines of the generation reduce skin inflammations, too [72].

\section{Anaphylaxis}

Antihistamines blocking $\mathrm{H} 1$ and/or $\mathrm{H} 2$ receptors are not the drugs of choice in anaphylaxis, and should not be used in monotherapy [73]. The antihistamines could be helpful in management of children with anaphylaxis as a second or third treatment line [74]. The intramuscular administration of the first generation antihistamines (e.g. clemastine or antazoline) could be considered - depending on the response to adrenaline (the first line drug), corticosteroids and salbutamol (the second line treatment) as well as the recent clinical status of the child [75].

\section{Primary mast cell activation syndromes}

There are no reliable studies in children, especially with the second generation antihistamines, although these drugs are used in clinical practice [76].

\section{Bilastine in children}

As of today, we only have studies regarding pharmacokinetics, pharmacodynamics, safety and tolerability of bilastine in children. The first trial showed that bilastine in the dose of $10 \mathrm{mg}$ used in children aged 2-12 gave the same (equivalent) exposure as the dose of $20 \mathrm{mg}$ in adults [77]. The second study, in children aged below 12 with allergic rhinoconjunctivitis or with chronic urticaria, indicated safety and tolerability (similar to placebo) of bilastine in the dose of $10 \mathrm{mg}$ used for 12 weeks [44].

\section{Conflict of interest}

Piotr Kuna has during the last 3 years received honoraria for participating in advisory board meetings or giving lectures for the following companies: Adamed, Allergopharma, AstraZeneca, Berlin Chemie, Boehringer Ingelheim, Celon Pharma, Chiesi, FAES, Meda, MSD, No- 
vartis, Pfizer, Polpharmex, Polpharma, Stallergen, Teva. Dariusz Jurkiewicz has during the last 3 years received honoraria for participating in advisory board meetings or giving lectures for the following companies: Adamed, Teva, Berlin-Chemie, Polpharma Magdalena CarneckaOperacz has during the last 3 years received honoraria for participating in advisory board meetings or giving lectures for the following companies: Novartis, BerlinChemie, Leo, Meda, Pierre Fabre, Genactive, Allergopharma. Rafat Pawliczak has the conflict of interest that applies to lecture fees and advisory honoraria paid by Berlin-Chemie Menarini. Jarosław Woron has during the last 3 years received honoraria for participating in advisory board meetings or giving lectures for the following companies: Berlin-Chemie/Menarini, MSD. Marcin Moniuszko has the conflict of interest that applies to received honoraria for participating during last 3 years in advisory board meetings or giving lectures for the following companies: Boehringer-Ingelheim, Berlin-Chemie/Menarini, Takeda, Symposion. Andrzej Emeryk reported lack of conflict of interest.

\section{References}

1. Bousquet J, Khaltaev N, Cruz AA, et al. Allergic rhinitis and its impact on asthma (ARIA) 2008 update (in collaboration with the World Health Organization, GA(2)LEN and AllerGen). Allergy 2008; 63: 80-160.

2. Bousquet J, Ansotegui I, Canonica GW, et al. Establishing the place in therapy of bilastine in the treatment of allergic rhinitis according to ARIA: evidence review. Curr Med Res Opin 2012; 28: 131-9.

3. Kuna P, Bachert C, Nowacki Z, et al. Efficacy and safety of bilastine $20 \mathrm{mg}$ compared with cetirizine $10 \mathrm{mg}$ and placebo for the symptomatic treatment of seasonal allergic rhinitis: a randomized, double-blind, parallel-group study. Clin Exp Allergy 2009; 39: 1338-47.

4. Bachert C, Kuna P, Zuberbier T. Bilastine in allergic rhinoconjuctivitis and urticaria. Allergy 2010; 65 (Suppl 93): 1-13.

5. Bousquet J, Van Cauwenberge P, Khaltaev N; Aria Workshop Group; World Health Organization. Allergic rhinitis and its impact on asthma. J Allergy Clin Immunol 2001; 108 (5 Suppl): S147-334.

6. Samoliński B, Sybilski AJ, Raciborski F, et al. Prevalence of rhinitis in Polish population according to the ECAP (Epidemiology of Allergic Disorders in Poland) study. Otolaryngol Pol 2009; 63: 324-30.

7. Brozek JL, Bousquet J, Baena-Cagnani CE, et al. Allergic Rhinitis and its Impact on Asthma (ARIA) guidelines: 2010 revision. J Allergy Clin Immunol 2010; 126: 466-76.

8. Polskie standardy leczenia nieżytów nosa (PoSLeNN). Stanowisko Panelu Ekspertów Polskiego Towarzystwa Alergologicznego. Medycyna Praktyczna, Kraków 2013.

9. Horak F, Zieglmayer P, Zieglmayer R, et al. The effects of bilastine compared with cetirizine, fexofenadine, and placebo on allergen-induced nasal and ocular symptoms in patients exposed to aeroallergen in the Vienna Challenge Chamber. Inflamm Res 2010; 59: 391-8.

10. Bachert C, Kuna P, Sanquer F, et al.; Bilastine International Working Group. Comparison of the efficacy and safety of bilastine $20 \mathrm{mg}$ vs desloratadine $5 \mathrm{mg}$ in seasonal allergic rhinitis patients. Allergy 2009; 64: 158-65.

11. Sastre J, Mullol J, Valero A, et al. Efficacy and safety of bilastine $20 \mathrm{mg}$ compared with cetirizine $10 \mathrm{mg}$ and placebo in the treatment of perennial allergic rhinitis. Curr Med Res Opin 2012; 28: 121-30.

12. Ferrer M. Immunological events in chronic spontaneous urticaria. Clin Transl Allergy 2015; 5: 30-8.

13. Zuberbier T. Urticaria. Allergy 2003; 58: 1224-34.

14. Zuberbier T, Aberer W, Asero R, et al. The EAACI/GA(2)LEN/ EDF/ WAO Guideline for the definition, classification, diagnosis and management of urticaria: the 2013 revision and update. Allergy 2014; 69: 868-87.

15. Krause K, Sophor A, Zuberbier T, et al. Up-dosing with bilastine results in improved effectiveness in cold contact urticaria. Allergy 2013; 68: 921-8.

16. Krause K, Sophor A, Zuberbier T, et al. High dose bilastine is effective in reducing temperature threshold in cold contact urticaria. Annual Scientific Meeting of the American College of Allergy, Asthma and Immunology, Anaheim, Nov 8-13, 2012.

17. Konstantinou GN, Asero R, Ferrer EF, et al. EAACI taskforce position paper: evidence for autoimmune urticaria and proposal for defining diagnostic criteria. Allergy 2013; 68: 27-36.

18. Carter NJ. Bilastine: in allergic rhinitis and urticaria. Drugs 2012; 72: 1257-69.

19. Church MK, Maurer M, Simons FE, et al. Risk of first-generation $\mathrm{H1}$-antihistamines: a GA(2)LEN position paper. Allergy 2010; 65: 459-66.

20. Craft TM, Nanden Bussche G, De Cree J, et al. ECG studies with astemizole. Hum Toxicol 1987; 6: 527-8.

21. No authors listed. Safety of terfenadine and astemizole. Med Lett Drugs Ther 1992; 34: 9-10.

22. Simons FE. H1-receptor antagonists. Comparative tolerability and safety. Drug Saf 1994; 10: 350-80.

23. McCue JD. Safety of antihistamines in the treatment of allergic rhinitis in elderly patients. Arch Fam Med 1996; 5: 464-8.

24. Genovese A, Spadaro G. Highlights in cardiovascular effects of histamine and H1-receptor antagonists. Allergy 1997; 52 (34 Suppl): 67-78.

25. Barbey JT, Anderson M, Ciprandi G, et al. Cardiovascular safety of second-generation antihistamines. Am J Rhinol 1999; 13: 235-43.

26. Estelle F, Simons R. H1-receptor antagonists: safety issues. Ann Allergy Asthma Immunol 1999; 83: 481-8.

27. Weissenburger J, Noyer M, Cheymol G, et al. Electrophysiological effects of cetirizine, astemizole and D-sotalol in a canine model of long QT syndrome. Clin Exp Allergy 1999; 29 (Suppl 3): 190-6.

28. Yap YG, Camm AJ. The current cardiac safety situation with antihistamines. Clin Exp Allergy 1999; 29 (Suppl 1): 15-24.

29. Gupta S, Banfield C, Kantesaria B, et al. Pharmacokinetic and safety profile of desloratadine and fexofenadine when coadministered with azithromycin: a randomized, placebocontrolled, parallel-group study. Clin Ther 2001; 23: 451-66.

30. Yao JA, Du X, Lu D, et al. Estimation of potency of HERG channel blockers: impact of voltage protocol and temperature. J Pharmacol Toxicol Methods 2005; 52: 146-53.

31. Graff C, Struijk JJ, Kanters JK, et al. Effects of bilastine on T-wave morphology and the QTc interval: a randomized, double-blind, placebo-controlled, thorough QTc study. Clin Drug Investig 2012; 32: 339-51. 
32. Church MK. Safety and efficacy of bilastine: a new H(1)-antihistamine for the treatment of allergic rhinoconjunctivitis and urticaria. Expert Opin Drug Saf 2011; 10: 779-93.

33. Conen S, Theunissen EL, Van Oers AC, et al. Acute and subchronic effects of bilastine (20 and $40 \mathrm{mg}$ ) and hydroxyzine (50 mg) on actual driving performance in healthy volunteers. J Psychopharmacol 2011; 25: 1517-23.

34. Corcostegui R, Labeaga L, Innerarity A, et al. Preclinical pharmacology of bilastine, a new selective histamine $\mathrm{H} 1$ receptor antagonist: receptor selectivity and in vitro antihistaminic activity. Drugs R D 2005; 6: 371-84.

35. Corcostegui R, Labeaga L, Innerarity A, et al. In vivo pharmacological characterisation of bilastine, a potent and selective histamine H1 receptor antagonist. Drugs R D 2006; 7: 219-31.

36. Jauregizar N, de la Fuente L, Lucero ML, et al. Pharmacokinetic-pharmacodynamic modelling of the antihistaminic (H1) effect of bilastine. Clin Pharmacokinet 2009; 48: 543-54.

37. Jauregui I, Garcia-Lirio E, Soriano AM, et al. An overview of the novel $\mathrm{H} 1$-antihistamine bilastine in allergic rhinitis and urticaria. Expert Rev Clin Immunol 2012; 8: 33-41.

38. Jauregui I, Ramaekers JG, Yanai K, et al. Bilastine: a new antihistamine with an optimal benefit-to-risk ratio for safety during driving. Expert Opin Drug Saf 1016; 15: 89-98.

39. Lasseter KC, Sologuren A, La Noce A, et al. Evaluation of the single-dose pharmacokinetics of bilastine in subjects with various degrees of renal insufficiency. Clin Drug Investig 2013; 33: 665-73.

40. Lucero ML, Arteche JK, Sommer EW, et al. Preclinical toxicity profile of oral bilastine. Drug Chem Toxicol 2012; 35 (Suppl 1): 25-33.

41. Lucero ML, Gonzalo A, Ganza A, et al. Interactions of bilastine, a new oral $\mathrm{H}_{1}$ antihistamine, with human transporter systems. Drug Chem Toxicol 2012; 35 (Suppl 1): 8-17.

42. Lucero ML, Gonzalo A, Mumford R, et al. An overview of bilastine metabolism during preclinical investigations. Drug Chem Toxicol 2012; 35 (Suppl 1): 18-24.

43. Mosges R, Lip Yen Lee D, Abong J, et al. Role of bilastine in the management of allergic rhinitis and urticaria: an AsiaPacific consensus statement. Asia Pac Allergy 2016; 6: 56-66.

44. Novak Z, Yanez A, Kiss I, et al. Safety and tolerability of bilastine $10 \mathrm{mg}$ administered for 12 weeks in children with allergic diseases. Pediatr Allergy Immunol 2016; 27: 493-8.

45. De Sutter AI, Saraswat A, van Driel ML. Antihistamines for the common cold. Cochrane Database Syst Rev 2015; 11: CD009345.

46. Helwig/Otto Arzneimittel. Ein Hundbuch fur Arzte und Apotheker. Der Deutsche Apotheker Verlag. Stuttgart, Deutschland 2011.

47. Bachert C, Maurer M. Safety and efficacy of desloratadine in subjects with seasonal allergic rhinitis and chronic urticaria: results of four postmarketing surveillance studies. Clin Drug Invest 2010; 30: 109-22.

48. Agrawal DK. Pharmacology and clinical efficacy of desloratadine as an anti-allergic and anti-inflammatory drug. Exp Opin Investig Drugs 2001; 10: 547-60.

49. Verster J, Pandi-Perumal SR, Ramaekers JG, et al. Drugs, driving and traffic safety. Birkhauser. Verlag, Switzerland 2009.

50. Choe JY. Drug Actions and Interactions. McGraw-Hill. New York, USA 2011.

51. Wells BG, DiPiro JT, Schwinghammer TL, et al. Pharmacotherapy handbook. McGraw-Hill, New York, USA 2015.

52. Hutchinson LC, Sleeper RB. Fundamentals of geriatric pharmacotherapy. ASHP Publications, Bethesda, USA 2015.
53. Bazire S. Psychotropic drug directory 2014. Lloyd-Reinhold Communications. Dorsington, UK 2014.

54. Hochadel MA. Mosby's drug reference for health professions. Elsevier, St. Louis, USA 2016.

55. Kuna P, Kruszewski J, Rogala B. Terapia anty-IgE. In: Standardy w alergologii. Vol. I. Kruszewski J, Kowalski ML. Medycyna Praktyczna, Kraków 2010; 175-90.

56. Rodrigo GJ, Neffen H, Castro-Rodriguez JA. Efficacy and safety of subcutaneous omalizumab vs placebo as add-on therapy to corticosteroids for children and adults with asthma: a systematic review. Chest 2011; 139: 28-35.

57. Braunstahl GJ, Chlumsky J, Peachey G, et al. Reduction in oral corticosteroid use in patients receiving omalizumab for allergic asthma in the real-world setting. Allergy Asthma Clin Immunol 2013; 9: 47.

58. Babu KS, Polosa R, Morjaria JB. Anti-IgE - emerging opportunities for omalizumab. Expert Opin Biol Ther 2013; 13: 765-77.

59. Fitzsimons R, van der Poel LA, Thornhill W, et al. Antihistamine use in children. Arch Dis Child Educ Pract Ed 2015; 100: 122-31.

60. Emeryk A, Leki przeciwhistaminowe w chorobach alergicznych - co jest ważne dla lekarza i pacjenta? Alergia 2009; 1: $29-32$.

61. Emeryk A. Leki przeciwhistaminowe u dzieci. Alergia 2010; 2: 11-4.

62. Simons FE, Simons KJ. Histamine and H1-antihistamines: celebrating a century of progress. J Allergy Clin Immunol 2011; 128: 1139-50.

63. Schad CA, Skoner DP. Antihistamines in the pediatric population: achieving optimal outcomes when treating seasonal allergic rhinitis and chronic urticaria. Allergy Asthma Proc 2008; 29: 7-13.

64. de Benedictis FM, de Benedictis D, Canonica GW. New oral $\mathrm{H} 1$ antihistamines in children: facts and unmeet needs. Allergy 2008; 63: 1395-404.

65. Carr W, Berstein J, Lieberman P, et al. A novel intranasal therapy of azelastine with fluticasone for the treatment of allergic rhinitis. J Allergy Clin Immunol 2012; 129: 1282-9.

66. Magerl M, Altrichter S, Borzova E, et al. The definition, diagnostic testing, and management of chronic inducible urticarias - The EAACI/GA(2)LEN/EDF/UNEV consensus recommendations 2016 update and revision. Allergy 2016; 71: 780-802.

67. de Silva D, Geromi M, Panesar SS, et al. Acute and longterm management of food allergy: systematic review. Allergy 2014; 69: 159-67.

68. Silny W, Gliński W, Czarnecka-Operacz M, et al. Leki przeciwhistaminowe w terapii dermatologicznej. W: Górski P. Leki przeciwhistaminowe. Zastosowanie w praktyce medycznej. Wydanie II. The UCB Institute of Allergy. Bruksela, Belgia 2005; 101-21.

69. van Zuuren EJ, Apfelbacher CJ, Fedorowicz Z, et al. No high level evidence to support the use of oral $\mathrm{H} 1$ antihistamines as monotherapy for eczema: a summary of a Cochrane systematic review. Syst Rev 2014; 3: 25.

70. Darsow U, Wollenberg A, Simon D, et al. ETFAD/EADV eczema task force 2009 position paper on diagnosis and treatment of atopic dermatitis. J Eur Acad Dermatol Venereol 2010; 24: 317-28.

71. Akdis CA, Akdis M, Bieber T, et al.; European Academy of Allergology and Clinical Immunology/American Academy of Allergy, Asthma and Immunology/PRACTALL Consensus Group. Diagnosis and treatment of atopic dermatitis in children and 
adults: European Academy of Allergology and Clinical Immunology/American Academy of Allergy, Asthma and Immunology/PRACTALL consensus report. Allergy 2006; 61: 969-87.

72. Wollenberg A, Oranje A, Deleuran M, et al. ETFAD/EADV Eczema task force 2015 position paper on diagnosis and treatment of atopic dermatitis in adult and paediatric patients. J Eur Acad Dermatol Venereol 2016; 30: 729-47.

73. Simonds FE, Ardusso LR, Bilo MB, et al. International consensus on (ICON) anaphylaxis. World Allergy Organ J 2014; 7: 9.

74. Simons FE, Ebisawa M, Sanchez-Borges M, et al. 2015 update of the evidence base: World Allergy Organization anaphylaxis guidelines. World Allergy Organ J 2015; 8: 32.

75. Muraro A, Roberts G, Clark P, et al. The management of anaphylaxis in childhood: position paper of the European Academy of Allergology and Clinical Immunology. Allergy 2007; 62: 857-71.

76. Nurmatov UB, Rhatigan E, Simons FE, et al. H1-antihistamines for primary mast cell activation syndromes: a systematic review. Allergy 2015; 70: 1052-61.

77. Wahn U, Valiente R, Vozmediano V, et al. $10 \mathrm{mg}$ of oral bilastine in 2 to 11 years old children has similar exposure to the adult therapeutic dose $(20 \mathrm{mg})$. Accepted Abstract. Pediatric Allergy and Asthma Meeting. 15-17 October 2015, Berlin, Germany. 